\title{
A Green Analytical Method Using Ultrasound in Sample Preparation for the Flow Injection Determination of Iron, Manganese, and Zinc in Soluble Solid Samples by Flame Atomic Absorption Spectrometry
}

\author{
M. Carmen Yebra \\ Department of Analytical Chemistry, Nutrition and Bromatology, Faculty of Chemistry, University of Santiago de Compostela, \\ Santiago de Compostela 15782, Spain \\ Correspondence should be addressed to M. Carmen Yebra, mcarmen.yebra@usc.es
}

Received 10 November 2011; Accepted 16 January 2012

Academic Editor: Xiu-Ping Yan

Copyright ( $) 2012$ M. Carmen Yebra. This is an open access article distributed under the Creative Commons Attribution License, which permits unrestricted use, distribution, and reproduction in any medium, provided the original work is properly cited.

\begin{abstract}
A simple and rapid analytical method was developed for the determination of iron, manganese, and zinc in soluble solid samples. The method is based on continuous ultrasonic water dissolution of the sample (5-30 mg) at room temperature followed by flow injection flame atomic absorption spectrometric determination. A good precision of the whole procedure (1.2-4.6\%) and a sample throughput of ca. 25 samples $\mathrm{h}^{-1}$ were obtained. The proposed green analytical method has been successfully applied for the determination of iron, manganese, and zinc in soluble solid food samples (soluble cocoa and soluble coffee) and pharmaceutical preparations (multivitamin tablets). The ranges of concentrations found were $21.4-25.61 \mu \mathrm{g} \mathrm{g}^{-1}$ for iron, $5.74-18.30 \mu \mathrm{g} \mathrm{g}^{-1}$ for manganese, and 33.27-57.90 $\mu \mathrm{gg}^{-1}$ for zinc in soluble solid food samples and 3.75-9.90 $\mu \mathrm{g} \mathrm{g}^{-1}$ for iron, $0.47-5.05 \mu \mathrm{g} \mathrm{g}-1$ for manganese, and $1.55-15.12 \mu \mathrm{gg}^{-1}$ for zinc in multivitamin tablets. The accuracy of the proposed method was established by a comparison with the conventional wet acid digestion method using a paired $t$-test, indicating the absence of systematic errors.
\end{abstract}

\section{Introduction}

Trace metal ions have important roles in our life because of involving a wide spectrum of activities. Iron, manganese, and zinc are essential trace elements, having several roles in many body functions [1].

Sample preparation is a key procedure in modern chemical analysis because it is one of the most time consuming and error-prone portions of any analytical scheme. In spite of major advances in the instrumentation used in determinative steps, many laboratories use sample preparation techniques that are time consuming and labor intensive. Sample dissolution is one of the most common operations in analytical chemistry. Because most quantitative techniques require that samples are introduced in liquid form, thousands of sample dissolutions are performed every working day in analytical laboratories. However, most conventional digestion procedures involving inorganic acids are tediously labor intensive, and a number of them are hazardous to laboratory workers and to the wider environment [2-4].

In order to avoid these drawbacks, sample introduction as slurry for different techniques can be an interesting approach. However, the use of chemical modifiers is required for slurry analysis by electrothermal atomic absorption spectrometry to obtain interference-free determinations, which increases the analysis cost and can cause sample contamination. However, the main drawback of this technique is the nonhomogeneity of the suspensions formed [5-7]. Ultrasound-assisted sample pretreatments offer an alternative approach to sample preparation prior to analysis. This energy facilitates and accelerates some analytical steps, decreasing the analysis time and the cost per analysis, increasing accuracy and precision (above all in a continuous mode) [8-12]. These methodologies have been applied to water insoluble samples, using a diluted inorganic acid (usually nitric acid) as extraction solution. Nevertheless, only three works were 


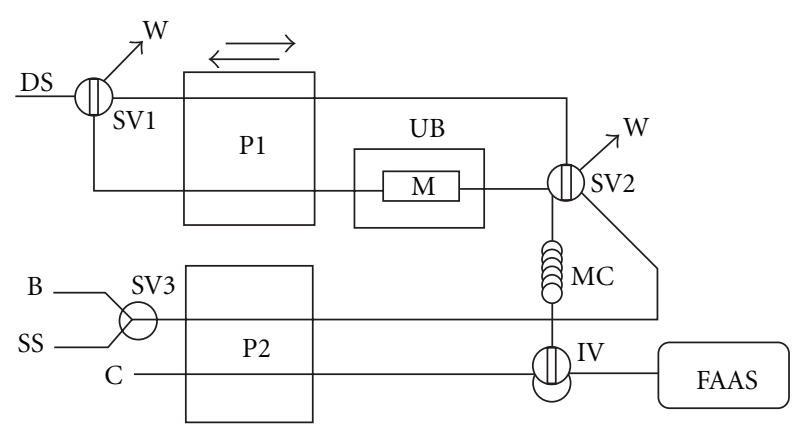

FIGURE 1: Experimental setup used for the continuous ultrasoundassisted dissolution step and FI determination of iron, manganese, and zinc in soluble samples. P1 and P2, peristaltic pumps; DS, dissolving solution; $\mathrm{W}$, waste; $\mathrm{UB}$, ultrasonic bath; $\mathrm{M}$, minicolumn containing the sample (dissolution cell); SS, standard solution; B, blank; IV, injection valve; SV1-SV3, switching valves; MC, mixing coil; C, carrier (ultrapure water); FAAS, flame atomic absorption spectrometer.

found in the literature reporting the use of continuous ultrasound-assisted approaches for dissolution of water soluble samples. These works were developed by our investigation team and are based on continuous milk powder water reconstitution for determination of zinc and iron, and on calcium and magnesium determination in soluble pharmaceutical tablets [13-15].

The food and pharmaceutical industry needs simple, accurate, and green analytical methods that can be routinely and safely used in the companies' own quality control laboratories. This work was focused on the study of the continuous ultrasound-assisted dissolution of water soluble foods and pharmaceutical samples. The continuous ultrasound dissolution system used is connected to a flow-injection (FI) manifold, which allows the continuous determination of trace metals by flame atomic absorption spectrometry (FAAS). The proposed method is based on the use of nontoxic reagents that makes it friendly both for the operator and the environment.

\section{Experimental}

2.1. Apparatus. The FI manifold used (Figure 1) has two sections: Section 1 where the solid sample is continuously dissolved, and Section 2 where the dissolved sample is led to the detector (FAAS) where the metals are continuously monitored. This manifold comprises two Gilson Minipuls-3 peristaltic pumps (Gilson, Villiers Le Bel, France) fitted with PVC tubes, an ultrasonic bath with an ultrasound power of $40 \mathrm{KHz}$ (Selecta, Barcelona, Spain), and a glass minicolumn used as sample container $(50 \mathrm{~mm} \times 3 \mathrm{~mm}$ i.d., bed volume $350 \mu \mathrm{L}$ ) (Omnifit, Cambridge, UK). The ends of the minicolumn were plugged with filter paper (Whatman 541). Four Rheodyne injection or switching valves models 5041 and 5301 (Rohnert Park, USA). A Perkin Elmer Model 5000 atomic absorption spectrometer (Perkin Elmer, Shelton, CTUSA) with a deuterium lamp as background correction system was used for iron, manganese, and zinc measurements. Hollow cathode lamps (Perkin Elmer) operating at recommended current were used. The instrument was set at $248.3,279.5$, and $213.9 \mathrm{~nm}$ for $\mathrm{Fe}, \mathrm{Mn}$, and $\mathrm{Zn}$ determination, respectively. The spectrometer output was connected to a Perkin Elmer Model 50 Servograph Recorder with a range of $5 \mathrm{mV}$. The signals measured were the heights of the absorbance peaks. Numerical analyses of experimental designs were performed by means of the statistical package Statgraphics Plus 5.1 (Manugistic, Inc. Rockville, MD, USA).

2.2. Reagents and Solutions. All chemicals were of analyticalreagent grade. Iron, manganese, and zinc standard solutions, $1000 \mu \mathrm{g} \mathrm{mL}^{-1}$, were supplied by Merck (Darmstad, Germany). Nitric acid 65\% and hydrochloric acid 30\% were obtained from Merck (Darmstad, Germany). All glassware used were cleaned in aqueous $4 \mathrm{~mol} \mathrm{~L}^{-1}$ nitric acid for four days and rinsed with ultrapure water before use. Ultrapure water with a resistivity of $18.2 \mathrm{M} \Omega \mathrm{cm}^{-1}$ was obtained from a Milli-Q purification system (Millipore Co., Bedford, MA, USA).

2.3. Procedure. Soluble solid samples were purchased from local markets and pharmacies. Pharmaceutical samples were grinded to a fine powder in a mortar, blended and homogenized, and finally sieved through a $0.1 \mathrm{~mm}$ pore diameter plastic sieve. All samples were kept in clean dry containers.

Solid soluble samples (5-30 mg) were directly weighed into the glass minicolumn (dissolution cell). Then, each minicolumn was assembled to the continuous ultrasoundassisted dissolution system, and immersed into the ultrasonic bath. After, the dissolution circuit was loaded with the dissolving solution ( $1 \mathrm{~mL}$ of ultrapure water). The dissolving solution is then circulated at $6 \mathrm{~mL} \mathrm{~min}^{-1}$ through the dissolution cell under ultrasonic irradiation during $2 \mathrm{~min}$ at room temperature. The direction of the flow was changed each $30 \mathrm{~s}$ to facilitate sample dissolution avoiding sample accumulation in the minicolumn ends. Once the sample is dissolved, the SV2 is switched to its other position, and the sample is led to the mixing coil where the solution is homogenized. Then, the loop of the injection valve (IV) is filled with a volume of $250 \mu \mathrm{L}$ of the sample solution, which is injected into an ultrapure water carrier stream that transport it at $3.5 \mathrm{~mL} \mathrm{~min}{ }^{-1}$ to the detector.

\section{Results and Discussion}

3.1. Optimization of the Continuous Dissolution Step. Six variables, namely, nitric acid concentration, hydrochloric acid concentration, temperature of the ultrasonic waterbath (dissolution temperature), ultrasound exposure time, dissolving solution volume, and flow-rate of the continuous dissolution manifold were selected to be examined. The studied variables as well as the values for each level (low and high) are shown in Table 1.

The consequence of changing a variable from low to high level value was examined on a selected response such as 
TABLE 1: Factor levels in the Plackett-Burman factorial design with their optimum values and analytical features of the method.

\begin{tabular}{|c|c|c|c|}
\hline Factor & Low & High & Optimum \\
\hline $\mathrm{HNO}_{3}$ concentration $\left(\mathrm{mol} \mathrm{L}^{-1}\right)$ & 0 & 3 & 0 \\
\hline $\mathrm{HCl}$ concentration $\left(\mathrm{mol} \mathrm{L}^{-1}\right)$ & 0 & 3 & 0 \\
\hline Ultrasound exposure time (min) & 0.5 & 5 & 2 \\
\hline Ultrasonic water-bath temperature $\left({ }^{\circ} \mathrm{C}\right)$ & 20 & 70 & 20 \\
\hline $\begin{array}{l}\text { Flow rate of the continuous ultrasound } \\
\text { dissolution system }\left(\mathrm{mL} \mathrm{min}^{-1}\right)\end{array}$ & 3.5 & 6 & 6 \\
\hline Dissolving solution volume (mL) & 1 & 3 & 1 \\
\hline \multicolumn{4}{|c|}{ Analytical features of the method } \\
\hline & $\mathrm{Fe}$ & $\mathrm{Mn}$ & $\mathrm{Zn}$ \\
\hline Calibration graph $^{\mathrm{a}}$ & $A=0.03 \mathrm{C}+4.8 \times 10^{-4}$ & $A=0.062 \mathrm{C}+2.2 \times 10^{-4}$ & $A=0.21 \mathrm{C}+5.2 \times 10^{-4}$ \\
\hline Correlation coefficient $\left(r^{2}\right)$ & 0.9997 & 0.9998 & 0.9998 \\
\hline $\operatorname{LOD}\left(\mu \mathrm{g} \mathrm{mL}^{-1}\right)$ & 0.02 & 0.01 & 0.03 \\
\hline LOQ $\left(\mu \mathrm{g} \mathrm{mL}^{-1}\right)$ & 0.06 & 0.05 & 0.1 \\
\hline Relative standard deviation (\%) & 2.4 & 4.6 & 1.2 \\
\hline
\end{tabular}

${ }^{\mathrm{a}} \mathrm{A}$, absorbance signal; C, concentration expressed as $\mu \mathrm{g} \mathrm{mL} \mathrm{m}^{-1}$.

percentage dissolution efficiency, according to the following equation:

$$
\% \text { dissolution efficiency }=\left(\frac{A}{B}\right) \times 100,
$$

where $A$ is the concentration of the metal obtained with the proposed procedure and $B$ the metal concentration obtained by a manual dissolution using a conventional digestion procedure with concentrated nitric acid and off-line FAAS detection [16].

A Plackett-Burman $2^{\wedge} 6^{*} 3 / 16$ factorial design with a center point (13 nonrandomized runs) was used to find the main factors affecting the continuous dissolution step. This factorial design was applied to a soluble cocoa sample and to a pharmaceutical preparation (soluble multivitamin tablet). The conclusions of the screening studies reflected that only the ultrasound exposure time was a statistically influential factor, and it was affected by a positive sign. The other variables were not statistically influential factors in the ranges studied at the $95 \%$ confidence level and all of them were affected by a positive sign. Although the concentration of the acids used as dissolving solution (nitric and hydrochloric acids) had a positive influence on the dissolution efficiency, a run of the experimental design achieved a quantitative \% dissolution efficiency with the minimum value of these variables $\left(0 \mathrm{~mol} \mathrm{~L}^{-1}\right)$. Thus, this minimum value was selected for subsequent experiments for the both factors, and ultrapure water was selected as dissolving solution. The dissolving solution volume and the ultrasonic water-bath temperature had a positive estimated effect, but these parameters yield small values for the main effects. Aiming to increase the analytical sensitivity and to make easy and rapid the sample dissolution step, was chosen as optimum the minimum value of these variables $\left(1 \mathrm{~mL}\right.$ and room temperature, $\left.20^{\circ} \mathrm{C}\right)$. Likewise, as the flow rate of the continuous ultrasound dissolution system had a positive sign, the maximum value tested for this variable $\left(6 \mathrm{~mL} \mathrm{~min}^{-1}\right)$ was chosen for subsequent experiments. According to the results, a new experimental design shifted in the direction of higher ultrasound exposure times would be desirable. However, this variable was fine tuning outside the framework of the design because a minor number of experiments were required. Then, several experiments were carried out in order to optimize the ultrasound exposure time, resulting in that the optimum value was $2 \mathrm{~min}$ for the two kinds of samples studied. All the optimum operational conditions are shown in Table 1.

The sample particle size was studied by a univariate method. For this were tested particle sizes between $0.03-$ $0.1 \mathrm{~mm}$. The results obtained indicated that this variable does not affect to the dissolution process within the range studied.

Other flow parameters involving iron, manganese, and zinc determination were also optimized. Thus, it was verified that with a mixing coil length of $199 \mathrm{~cm}$ (equivalent to $1.0 \mathrm{~mL}$, which is the volume of the dissolving solution) was obtained a complete homogenization of the sample solution. The carrier flow rate and the injected sample volume were also studied. The carrier flow rate was tested between $3-6 \mathrm{~mL} \mathrm{~min}^{-1}$, and the injected volume of the sample solution between $100-300 \mu \mathrm{L}$. The aspiration flow rate of the nebulizer was adjusted to be the same as the flow rate of the carrier solution. Although the highest aspiration flow rate provides the best sensitivity, a high dispersion takes place because at the same time was increased the carrier flow rate. Therefore, a carrier flow rate of $3.5 \mathrm{~mL} \mathrm{~min}^{-1}$ (dispersion equal to 1.1) was chosen as a compromise to obtain the minimum dispersion in the flow system. With regard to the injected sample volume, it was verified that when the volume was increased, the sensitivity was also increased. Therefore, a volume of $250 \mu \mathrm{L}$ was chosen as optimum, which in addition allows to inject several times the sample solution to verify its homogeneity. 
TABLE 2: Determination of Fe, Mn, and $\mathrm{Zn}$ in soluble foods and pharmaceutical samples and paired $t$-test.

\begin{tabular}{|c|c|c|c|c|c|c|}
\hline \multirow{3}{*}{$\begin{array}{l}\text { Samples } \\
\text { Soluble food sample }\end{array}$} & \multicolumn{6}{|c|}{ Concentration, mean \pm standard deviation $(n=3)\left(\mu \mathrm{g} \mathrm{g}^{-1}\right)$} \\
\hline & \multicolumn{2}{|c|}{$\mathrm{Fe}$} & \multicolumn{2}{|c|}{$\mathrm{Mn}$} & \multicolumn{2}{|c|}{$\mathrm{Zn}$} \\
\hline & Official method & Present method & Official method & Present method & Official method & Present method \\
\hline Soluble cocoa & $20.31 \pm 1.63$ & $21.42 \pm 0.65$ & $5.31 \pm 0.55$ & $5.74 \pm 0.21$ & $55.41 \pm 2.91$ & $57.90 \pm 1.00$ \\
\hline Soluble coffee 1 & $43.77 \pm 1.75$ & $44.71 \pm 0.71$ & $17.14 \pm 0.55$ & $18.30 \pm 0.34$ & $54.14 \pm 1.87$ & $53.18 \pm 0.68$ \\
\hline Soluble coffee 2 & $24.16 \pm 1.00$ & $25.61 \pm 0.65$ & $15.07 \pm 0.80$ & $14.11 \pm 0.34$ & $32.22 \pm 1.45$ & $33.27 \pm 0.68$ \\
\hline \multicolumn{7}{|c|}{ Concentration, mean \pm standard deviation $(n=3)($ mg per tablet $)$} \\
\hline $\begin{array}{l}\text { Pharmaceutical } \\
\text { preparations }\end{array}$ & $\begin{array}{c}\text { Nominal } \\
\text { concentration }\end{array}$ & Present method & $\begin{array}{c}\text { Nominal } \\
\text { concentration }\end{array}$ & Present method & $\begin{array}{c}\text { Nominal } \\
\text { concentration }\end{array}$ & Present method \\
\hline Multivitamin tablet 1 & 10.0 & $9.90 \pm 0.01$ & 5.0 & $5.05 \pm 0.02$ & 15.0 & $15.12 \pm 0.03$ \\
\hline Multivitamin tablet 2 & 3.6 & $3.75 \pm 0.02$ & 0.5 & $0.47 \pm 0.01$ & 3.0 & $2.84 \pm 0.02$ \\
\hline Multivitamin tablet 3 & 5.6 & $5.61 \pm 0.03$ & 1.4 & $1.35 \pm 0.02$ & 1.4 & $1.55 \pm 0.02$ \\
\hline
\end{tabular}

Critical value of $t(P=0.05)=2.57$; experimental value of $t: 2.20$ for $\mathrm{Fe}, 0.35$ for $\mathrm{Mn}$, and 0.92 for $\mathrm{Zn}$.

3.2. Analytical Figures of Merit. As can be seen in Table 1, calibration curves were obtained by using a linear plot of the peak height as a function of the standard concentrations of each analyte $(n=7)$. In order to evaluate matrix interferences, the slopes obtained from analytical and analyte addition curves were compared. For this, a cocoa soluble sample and a pharmaceutical preparation (soluble multivitamin tablet) were spiked with several concentrations of the analytes, which were added as dissolving solution into the continuous ultrasound dissolution system. The addition calibration graphs were run $(n=7)$ under the optimal chemical and flow conditions for the whole process. These equations and their corresponding calibration graphs have the same slope, demonstrating that the determination of iron, manganese, and zinc is free of matrix interferences. The limits of detection (LOD) and quantification (LOQ) were calculated as the mass of analyte which gives a signal $3 \sigma$ or $10 \sigma$, for LOD and LOQ, respectively, above the mean blank signal (where $\sigma$ is the standard deviation of the blank signal, $n=30$ ). The values obtained for LOD and LOQ are shown in Table 1 . The precision of the continuous analytical method was checked using a sample containing $21.42 \mu \mathrm{g} \mathrm{g}^{-1}$ $\mathrm{Fe}, 5.74 \mu \mathrm{g} \mathrm{g}^{-1} \mathrm{Mn}$, and $57.90 \mu \mathrm{g} \mathrm{g} \mathrm{g}^{-1} \mathrm{Zn}$ (soluble cocoa), and the results expressed as relative standard deviation $(n=$ 11) are also shown in Table 1. The sample throughput of the proposed methodology, taking into account the whole process, was ca. 25 samples per hour.

3.3. Analysis of Real Samples. The method was applied to the determination of iron, manganese, and zinc in water soluble food samples and pharmaceutical preparations (soluble multivitamin tablets). The results obtained expressed as $\mu \mathrm{gg}^{-1}$ dry weight and their standard deviation $(n=3)$ are shown in Table 2. The results obtained for food samples were compared with those obtained by employing a wet acid digestion method [16] on same samples by using the paired $t$-test. As is reported in Table 2, both groups of results do not give significantly different values, thus the agreement between them is satisfactory at 95\% confidence level.

\section{Conclusions}

The use of a continuous ultrasound-assisted dissolution system coupled to an FI manifold using ultrapure water as dissolving solution is confirmed to be an interesting tool for the automatic dissolution of soluble solid samples of different nature. This continuous manifold allows the dissolution of a sample in a time shorter than that required by a batch sample dissolution procedure. Furthermore, this methodology provides accurate results with high precisions, because there are not sample losses as result of its manipulation, and does not present random errors associated to glassware calibration. The proposed method can be considered as environmentally friendly at every step of the analytical procedure. All these characteristics make the method easy to apply to quality control in industry.

\section{Acknowledgment}

This work has been funded by Spain's Ministry of Science and Innovation, within the framework of Project CTQ200912282.

\section{References}

[1] A. Kocyigit, F. Armutcu, A. Gurel, and B. Ermis, "Alterations in plasma essential trace elements selenium, manganese, zinc, copper, and iron concentrations and the possible role of these elements on oxidative status in patients with childhood asthma," Biological Trace Element Research, vol. 97, no. 1, pp. 31-41, 2004.

[2] J. Sastre, A. Sahuquillo, M. Vidal, and G. Rauret, "Determination of $\mathrm{Cd}, \mathrm{Cu}, \mathrm{Pb}$ and $\mathrm{Zn}$ in environmental samples: microwave-assisted total digestion versus aqua regia and nitric acid extraction," Analytica Chimica Acta, vol. 462, no. 1, pp. 59-72, 2002.

[3] M. Ghaedi, A. Shokrollahi, A. H. Kianfar et al., "Preconcentration and separation of trace amount of heavy metal ions on bis(2-hydroxy acetophenone)ethylendiimine loaded on activated carbon," Journal of Hazardous Materials, vol. 162, no. 2-3, pp. 1408-1414, 2009. 
[4] Y. Luo, B. Zhang, M. Chen et al., "Rapid and simultaneous determination of essential minerals and trace elements in human milk by improved flame atomic absorption spectroscopy (FAAS) with microwave digestion," Journal of Agricultural and Food Chemistry, vol. 58, no. 17, pp. 9396-9400, 2010.

[5] G. A. Zachariadis and A. F. Olympiou, "Use of slurry suspension sample introduction technique in fast multielement analysis of multimineral and multivitamin formulations by inductively coupled plasma atomic emission spectrometry," Journal of Pharmaceutical and Biomedical Analysis, vol. 47, no. 3, pp. 541-546, 2008.

[6] G. A. Zachariadis and E. Sahanidou, "Multi-element method for determination of trace elements in sunscreens by ICPAES," Journal of Pharmaceutical and Biomedical Analysis, vol. 50, no. 3, pp. 342-348, 2009.

[7] S. L. C. Ferreira, M. Miró, E. G. P. Da Silva et al., "Slurry sampling-an analytical strategy for the determination of metals and metalloids by spectroanalytical techniques," Applied Spectroscopy Reviews, vol. 45, no. 1, pp. 44-62, 2010.

[8] M. C. Yebra-Biurrun and S. Cancela-Pérez, "Continuous approach for ultrasound-assisted acid extraction-minicolumn preconcentration of chromium and cobalt from seafood samples prior to flame atomic absorption spectrometry," Analytical Sciences, vol. 23, no. 8, pp. 993-996, 2007.

[9] M. C. Yebra-Biurrun and R. M. Cespón-Romero, "Fast ultrasound-assisted extraction of copper, iron, manganese and zinc from human hair samples prior to flow injection flame atomic absorption spectrometric detection," Analytical and Bioanalytical Chemistry, vol. 388, no. 3, pp. 711-716, 2007.

[10] M. C. Yebra, S. Cancela, and R. M. Cespón, "Automatic determination of nickel in foods by flame atomic absorption spectrometry," Food Chemistry, vol. 108, no. 2, pp. 774-778, 2008.

[11] N. Jalbani, T. G. Kazi, M. K. Jamali et al., "Application of fractional factorial design and doehlert matrix in the optimization of experimental variables associated with the ultrasonic-assisted acid digestion of chocolate samples for aluminum determination by atomic absorption spectrometry," Journal of AOAC International, vol. 90, no. 6, pp. 1682-1688, 2007.

[12] T. G. Kazi, M. K. Jamali, M. B. Arain et al., "Evaluation of an ultrasonic acid digestion procedure for total heavy metals determination in environmental and biological samples," Journal of Hazardous Materials, vol. 161, no. 2-3, pp. 13911398, 2009.

[13] M. C. Yebra, A. Moreno-Cid, S. Cancela, and R. M. Cespón, "Flow injection AAS determination of zinc in milk powder and infant formula using continuous ultrasound-assisted dissolution for soluble solid sample preparation," Atomic Spectroscopy, vol. 24, no. 6, pp. 218-221, 2003.

[14] M. C. Yebra, A. Moreno-Cid, R. Cespón, and S. Cancela, "Preparation of a soluble solid sample by a continuous ultrasound assisted dissolution system for the flow-injection atomic absorption spectrometric determination of iron in milk powder and infant formula," Talanta, vol. 62, no. 2, pp. 403-406, 2004.

[15] M. C. Yebra, "Flow injection determination of calcium and magnesium in soluble pharmaceutical tablets by flame atomic absorption spectrometry using ultrasound for sample preparation," Atomic Spectroscopy, vol. 32, no. 2, pp. 80-84, 2011.

[16] Association of Official Analytical Chemists, in Official Methods of Analysis: Lead, Cadmium, Zinc, Copper, and Iron in Foods Sec. 999.10, AOAC, Arlington, Va, USA, 17th edition, 2002. 


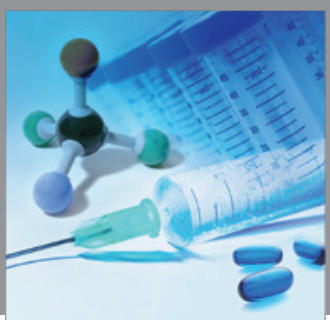

International Journal of

Medicinal Chemistry

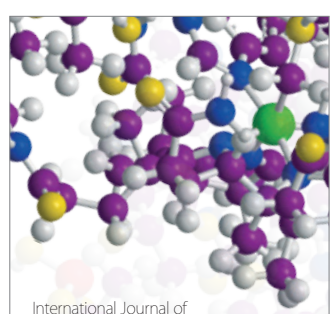

Carbohydrate Chemistry

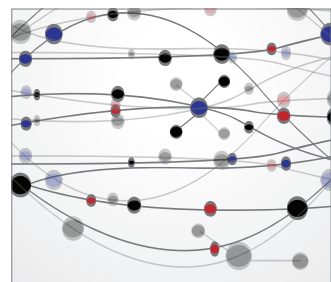

The Scientific World Journal
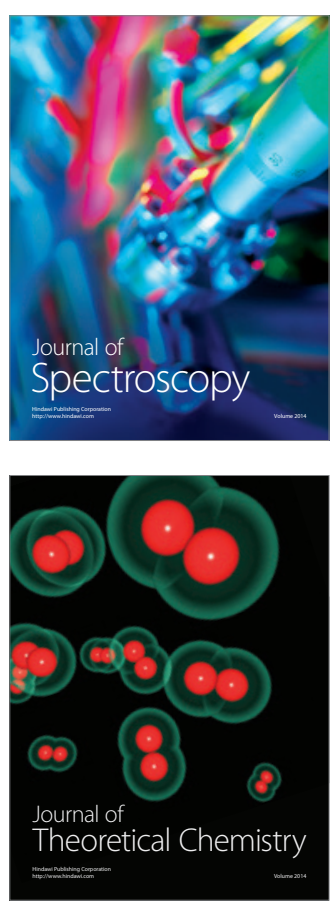
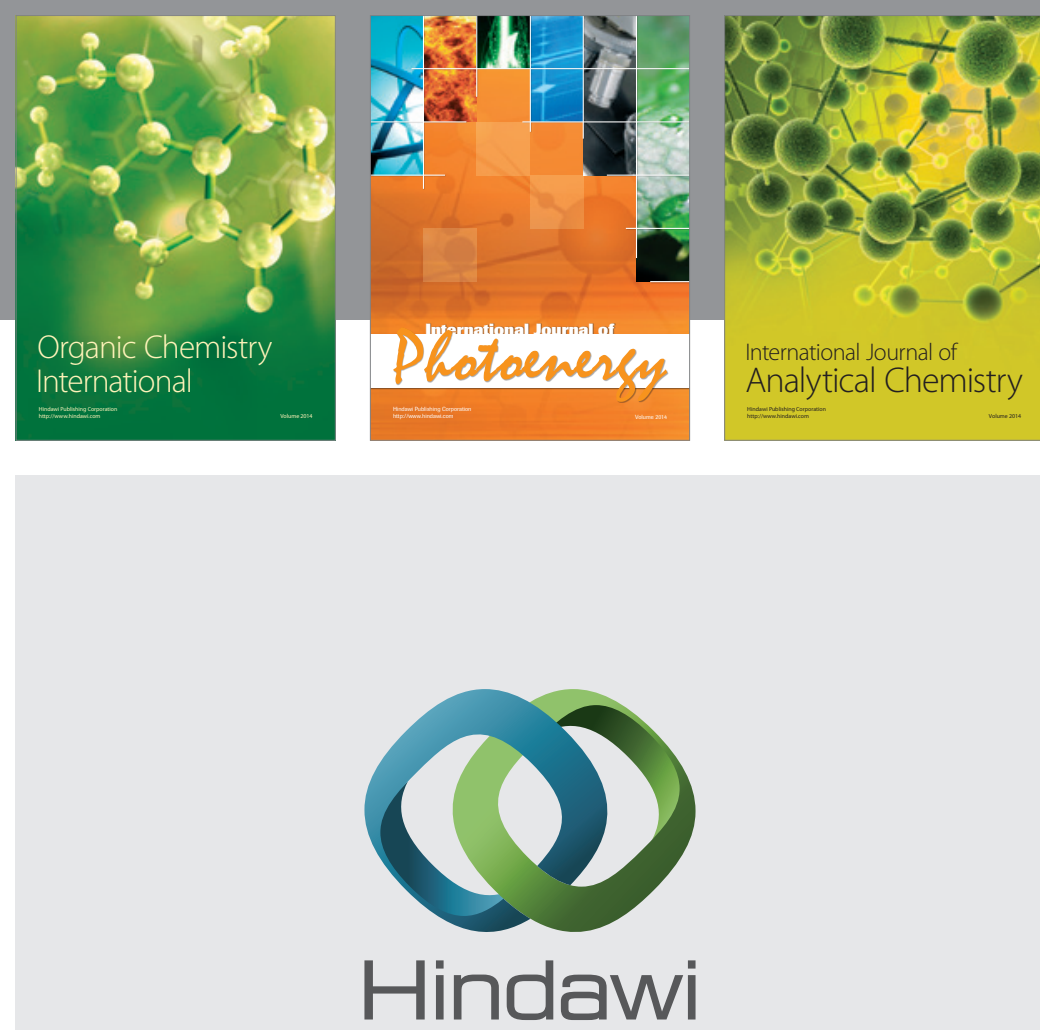

Submit your manuscripts at

http://www.hindawi.com
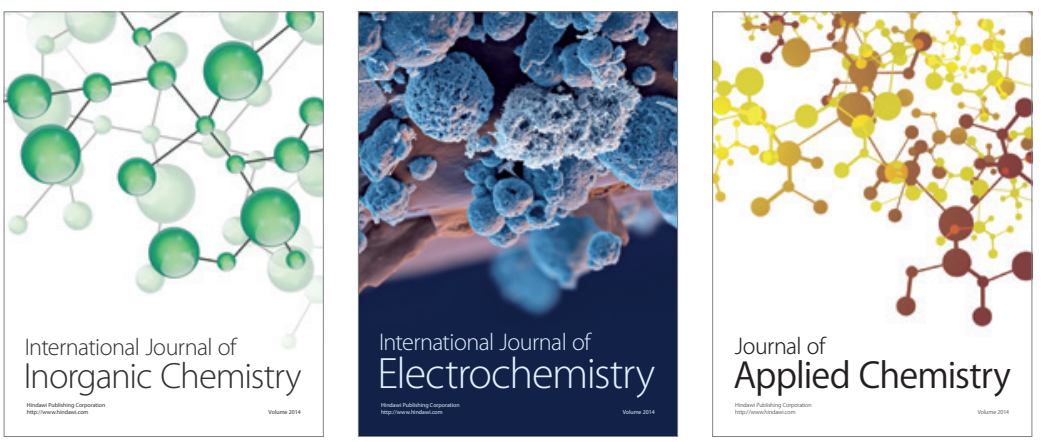

Journal of

Applied Chemistry
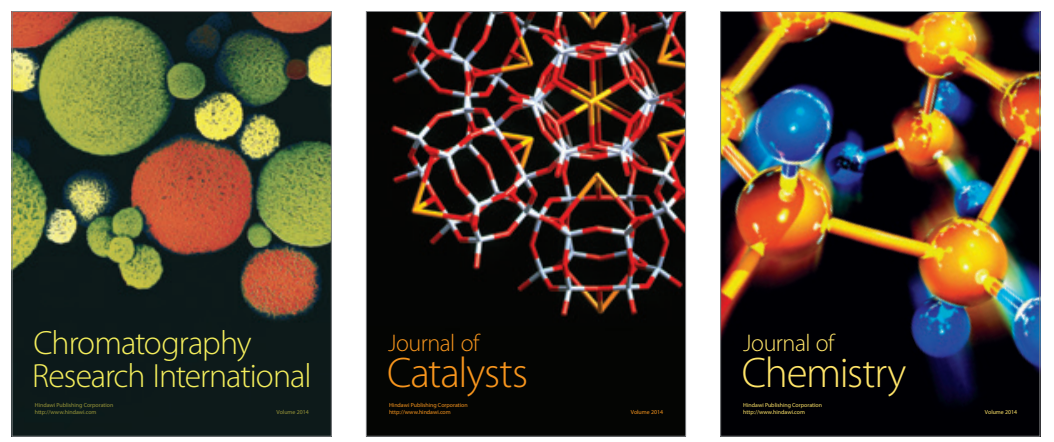
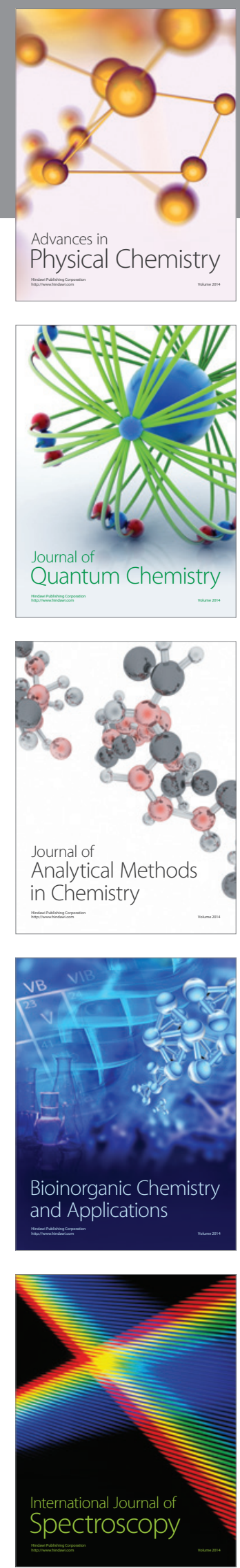